\title{
CUATRO ESCENARIOS PARA UNA TRANSICIÓN POLÍTICA EN CUBA *
}

\author{
Esther del Campo y Víctor Peralta"
}

Bajo este título, pretendemos brevemente presentar y someter a discusión los posibles escenarios que hemos previsto para la evolución de la actual coyuntura cubana. El momento presente puede resultar crucial para el tránsito a la democracia en Cuba, pero no pretendemos sin embargo "prescribir o augurar" el futuro político de la isla. Se trataría más bien de analizar las posibles estrategias que se ofrecen a los distintos actores implicados en la evolución política, social y económica de Cuba, priorizando cinco elementos en nuestro análisis: el escenario de poder, la economía, la ideología, las relaciones internacionales y la sociedad civil; cuestionar la validez de la aplicación de modelos de transición exógenos como podrían ser los de Europa del Sur (especialmente, España y Portugal), América Latina (principalmente, los del Cono Sur) y Europa del Este (en este ámbito, las similitudes pero también las diferencias pueden ser mayores); interpretar y validar el significado real del liderazgo histórico de Fidel Castro. En este sentido, cabría preguntarse si podremos identificar el liderazgo de Castro como un tipo de nacionalismo carismático, de caudillismo populista, o incluso, si tiene algunas características que lo pudieran equiparar al típico dictador latinoamericano de la década del setenta.

Consideramos, en primer lugar, el que nos parece el escenario más verosímil de esta supuesta transición cubana que puede culminar con la democratización del régimen: la transición de un régimen totalitario a un régimen autoritario. Se trataría de una transformación dirigida desde dentro del régimen totalitario, e iniciada por los militares como gobierno. Siguiendo la clásica distinción de Linz (1964) entre regímenes totalitarios y autoritarios, Cuba parece estar abandonando el modelo totalitario, impuesto durante la década de los sesenta y que caracterizó al régimen de Fidel Castro hasta 1989 para transitar en los años noventa hacia un régimen autoritario que puede denominarse como de autoritarismo nacionalista (Domínguez, 1997) ${ }^{2}$. Este planteamiento no significa que la evolución del totalitarismo al autoritarismo se produzca dentro de un continuum y que el segundo sea una de las consecuencias necesarias del primero; en este caso y como se ha demostrado ampliamente por la doctrina desde la década del setenta, los cam- bios sociales, políticos y económicos dentro de un régimen político no son siempre ni acumulables ni consecutivos y pueden ofrecernos distintas cristalizaciones de la evolución de la estructura política de ese mismo régimen.

Más recientemente, Linz y Stepan (1997: 42-51) han abordado el análisis de los regímenes no democráticos, dotando a los postotalitarismos de una entidad propia ${ }^{2}$ y distinguiendo incluso varios subtipos: a) el postotalitarismo temprano se aproxima mucho al tipo totalitario ideal pero se diferencia de éste al menos en una dimensión, que consiste normalmente en la imposición de algún tipo de restricción al líder; b) puede hablarse de postotalitarismo congelado en aquella situación en que, a pesar de la tolerancia persistente de algún tipo de crítica por parte de la sociedad civil, casi todos los mecanismos de control del partido y del Estado permanecen estáticos durante bastante tiempo, sin evolucionar en un sentido u otro; y c) cabe calificar al régimen de postotalitarismo maduro, cuando se ha producido un cambio significativo en casi todas las dimensiones del régimen postotalitario (liderazgo, pluralismo, ideología y movilización), pero políticamente el partido oficial sigue conservando un lugar preferente dentro del sistema político. Esto hace que una buena parte de los autores que defienden el nuevo autoritarismo cubano lo identifiquen sin más con este nuevo tipo postotalitario (Domínguez, 1997:21).

* Queremos agradecer especialmente al Instituto Universitario Ortega y Gasset y al Dr. Carlos Malamud, la iniciativa de esta investigación así como sus comentarios y aportaciones a la misma; sin embargo, las carencias y déficits son de la estricta responsabilidad de los autores.

** Universidad Complutense de Madrid e Instituto Universitario Ortega y Gasset.

*** Consejo Superior de Investigaciones Científicas e Instituto Universitario Ortega y Gasset.

1. Linz (1964) ha definido los regímenes autoritarios como sistemas políticos con un pluralismo limitado, no responsable; sin una ideología elaborada y directora (pero con una mentalidad peculiar); carentes de una movilización política intensa o extensa (excepto en algunos puntos de su evolución), y en los que un líder (o si acaso un grupo reducido) ejerce el poder dentro de límites formalmente mal definidos, pero en realidad bastante predecibles. Domínguez (1997), partiendo de este análisis, insiste en que uno de los rasgos más peculiares de la Cuba autoritaria es la particular insistencia por parte del régimen en la defensa de la nación y de la soberanía; de ahí, su caracterización del régimen cubano como de autoritarismo nacionalista.

2. Dado que Linz ya en 1975 había abordado el análisis de los regímenes postotalitarios pero como un subtipo dentro de los autoritarismos. 
Quizás y no convendría olvidarlo que lo más característico de un régimen autoritario es la liberalización ${ }^{3}$ que crece entre los distintos actores políticos del mismo régimen, continuistas, reformistas y rupturistas (éstos en el exilio), rompiendo la pretendida homogeneidad ideológica impuesta desde la cúpula del Estado totalitario. Este escenario verosímil en el que se espera que el modelo autoritario no termine perpetuándose, pero sí que dure hasta que el liderazgo de Castro se interrumpa por su retiro o muerte, se caracterizará por lo siguiente:

1) El escenario del poder: Las Fuerzas Armadas Revolucionarias (FAR) asumirán un protagonismo más importante en la política interior cubana, en la medida en que el Estado siga debilitándose en su control y represión sobre los movimientos disidentes locales, sector cuyo liderazgo será compartido por los activistas sociales y los movimientos católicos. En este sentido, interpretamos que probablemente la Comisión Cubana de Derechos Humanos y Reconcialiación Nacional de Elizardo Sánchez Santacruz, juegue un papel más influyente en la política doméstica. Asímismo, también el exilio tiene mayores posibilidades de filtración y apoyo sobre organizaciones cubanas de disidentes del interior.

2) La economía: El Estado seguirá debilitándose en su control de las actividades económicas de la isla, especialmente por el comportamiento errático de la economía en el período 1989-1993 (en este sentido, cabría preguntarse si el repunte económico que parece haberse producido a partir de 1994, reforzaría o no este proceso de desestatalización). No cabe duda sin embargo, que la crisis ha producido un debilitamiento aún mayor del mercado interior por la crisis de insumos para las principales industrias. Por el contrario, las acciones manifestadas por el gobierno en los últimos tiempos, especialmente después de la visita del Papa; el régimen ha seguido frustrando cualquier actividad que pudiera interpretarse como de crítica u oposición al modelo cubano (a primeros de septiembre de este mismo año, 1998, fueron detenidas varias personas, pertenecientes a diferentes organizaciones sociales aceptada como miembro beneficiario del club de países de Africa, el Caribe y el Pacífico (ACP), y por tanto, beneficiario de las ayudas de la UE. En el frente interno, las Unidades Básicas de Producción Cooperativa (UBPC $)^{4}$ pasarán a depender más de las decisiones tomadas por los propios socios cooperativistas que de los dictados del gobierno. Por otro lado, crecerá abismalmente la actividad informal y clandestina de la sociedad cubana, hasta ahora controlada por el Estado. En esta línea, se producirá una pérdida de influencia cada vez más importante de las organizaciones sindicales patrocinadas por el Partido de la Revolución tales como la Confederación de Trabajadores de Cuba (CTC), el Comité de Defensa de la Revolución (CDR) y la Federación de Mujeres de Cuba (FMC). De este modo, el gobierno autoritario tarde o temprano se verá precisado a adoptar un modelo de apertura económica parecido al vietnamita o chino (por supuesto, con las debidas diferencias especialmente respecto a este último país), aunque los costos sociales serán imprevisibles al ocurrir ello en una sociedad predominantemente urbana a diferencia de los dos casos anterio- res. Estos procesos se darán paralelamente a un aumento del efecto demostración provocado por la creciente presencia de turistas en la isla, y si se produce, una cierta liberalización de los medios de comunicación.

3) La ideología: Se producirá una mayor profundización del ideario nacionalista en detrimento del mensaje marxista-leninista que se irá opacando gradualmente. La simbología exclusiva será Martí y Castro, es decir, nacionalismo y socialismo. La desideologización comunista será completada por un retorno a las raíces "guevaristas" (el rescate del concepto del "hombre nuevo", del "trabajo voluntario"). La supervivencia ideológica del régimen cubano quedará más que nunca adherida a la supervivencia biológica de Fidel Castro. Se dará también por concluida la circulación de las élites que empezó en los años ochenta ${ }^{5}$ (lo que podría provocar un proceso de ruptura en el interior de los continuistas dada la posibilidad entreabierta de controlar el proceso de transición) ${ }^{6}$. El delfín de Fidel Castro puede ser transitoriamente su hermano Raúl dado su control sobre las FAR o un representante de la nueva generación castrista que podría estar formándose en el interior de la Asamblea Nacional Popular (ANP).

4) Las relaciones internacionales: Durante esta etapa, el embargo norteamericano se suavizará y no se producirán más leyes al estilo de la Ley Torricelli o de la Ley HelmsBurton, que probablemente se derogará. Estados Unidos adoptará un compás de espera sin renunciar a sus exigen-

3. En un contexto no democrático, entendemos, tomando la definición que nos ofrecen Linz y Stepan (1997:3), la liberalización como una combinación de cambios políticos y sociales, tales como una menor censura de los medios de comunicación, un mayor espacio para la organización de actividades autónomas por parte de los trabajadores, la introducción de algunas salvaguardias para los individuos tales como el habeas corpus, la libertad para la mayoría de los presos políticos, el retorno de los exiliados, quizás algunas medidas para la mejora en la distribución de los ingresos, y lo más importante, la tolerancia respecto a la oposición. En el caso cubano, la tolerancia del régimen con respecto a la oposición es relativamente débil, a pesar de las buenas intenciones manifestadas por el gobierno en los últimos tiempos, especialmente después de la visita del Papa, el régimen ha seguido frustrando cualquier actividad que pudiera interpretarse como de crítica u oposición al modelo cubano (a primeros de septiembre de este mismo año, 1998, fueron detenidas varias personas, pertenecientes a diferentes organizaciones sociales como el Comité Cubano de Opositores Pacíficos, el Colegio Independiente de Pedagogos, o periodistas pertenecientes al Buró de Prensa Independiente de Cuba). Sin embargo, paralelamente se permitió la mayor manifestación religiosa desde 1959 con motivo de la celebración del día de la Virgen de la Caridad del Cobre; esto explicaría la paradoja, de un paulatino debilitamiento del poder del Estado que abre espacios a la oposición, pero que a su vez conduce a un aumento de la represión por parte del mismo Estado.

4. En septiembre de 1993, el gobierno cubano aprobó la transformación de las granjas estatales en UBPC, que rápidamente y a pesar de la inercia adquirida en los años anteriores, empezaron a demandar mayor participación en las decisiones.

5. Como señala acertadamente Domínguez (1997:19) entre 1965 y 1980, no hubo ningún cambio en la membrecía del Buró Político del Partido Comunista. Al finalizar el IV Congreso del Partido en 1991, sólo quedaban cinco de quienes fueron miembros del Buró Político en 1975 los hermanos Castro, Juan Almeida, Carlos Rafael Rodríguez, y José Ramón Machado.

6. En este sentido, son interesantes las lecciones de la Europa de Este interpretadas en el nuevo pragmatismo de una parte de las élites políticas del viejo régimen que se dan cuenta de las posibilidades, no sólo institucionales sino también privadas, que ofrece un proceso de apertura controlada. 
cias contenidas en las reclamaciones de compensación económica ${ }^{7}$. Una vez desaparecido Fidel Castro, Estados Unidos cobrará una singular importancia en la transición política cubana pero no es previsible sin embargo, una invasión sino más bien una actuación a través de los grupos exiliados de Miami y Madrid y, en menor medida, de la disidencia que ha surgido dentro de la isla ${ }^{8}$. Las relaciones diplomáticas con la Unión Europea se mantendrán en el ritmo en que se encuentran en la actualidad. No habrá un incremento de la actividad empresarial pública en Cuba por parte de los gobiernos europeos. Las relaciones con España se intensificarán sobre todo en el terreno de los contactos culturales a través de la embajadas. América Latina seguirá teniendo un papel secundario en la transición cubana, dependiendo sus actos de lo que haga Estados Unidos.

5) La sociedad civil: Se mostrará cada vez más distanciada del régimen aunque no se adentrará a una actuación política autónoma ya que le será muy difícil sortear los mecanismos represivos y de control-censura vecinal que el Estado seguirá aplicando. Es probable que el régimen permita que la disidencia interna pueda organizarse en una especie de movimiento demócrata-cristiano con voz en la ANP. Otras organizaciones sociales, principalmente la Iglesia Católica, pero también otros grupos como las organizaciones de derechos humanos, gremiales, comunitarias, tendrán mayores posibilidades de autoorganizarse y de manifestarse públicamente, en este caso las más beneficiadas serán las organizaciones católicas, frente al resto que seguirán sufriendo un mayor control. A pesar de una cierta liberalización autoimpuesta por el gobierno, los medios de comunicación seguirán en su totalidad controlados por el Estado y no se permitirán que surjan diarios ni radios controlados por la sociedad civil disidente. Es improbable que la sociedad civil pueda participar en una elección libre, la modalidad inventada por Castro de señalar los candidatos que ocuparán todos los curules de la Asamblea Popular y que los electores sólo deben confirmar, se mantendrá.

La verosimilitud de un escenario como el que acabamos de plantear no significará por supuesto que la evolución se adecúe en todos los aspectos a los que nosotros nos hemos atrevido a apuntar, sino que sería previsible que en un régimen autoritario se fuera produciendo un acomodamiento de los distintos actores implicados en el régimen, gobierno, FAR, disidencia interna y externa, Iglesia Católica, organizaciones sociales, etc. De este acomodamiento y de los posibles acuerdos ulteriores que se fueran produciendo en torno a la regulación y funcionamiento del sistema político para todos los actores implicados, dependerá en última instancia que el régimen autoritario avance o no hacia una transición democrática. No hay que olvidar que los regímenes autoritarios no tienen que necesariamente encontrarse en proceso de transición hacia un diferente tipo de régimen. Como demostró Linz en sus clásicos estudios sobre la España autoritaria de los cincuenta y de los sesenta (1970), el régimen autoritario podía funcionar como un sistema relativamente integrado durante un período de tiempo relativamente estable.

\section{II}

En segundo lugar, consideramos que un escenario inverosímil vendría dado en estas circunstancias por una transición impuesta por Estados Unidos. Este escenario se correspondería, siguiendo a Stepan (1986:71-72) con una instalación externamente dirigida. Sólo sería posible que ocurriera mediante una intervención armada de las fuerzas militares estadounidenses presionadas por los lobbies hispano-cubanos para resolver, drásticamente, el problema generado por la persistente negativa de Castro de hacer algún tipo de apertura de su régimen socialista, o quizás también ante una situación de descontrol y desgobierno a la muerte de éste.

La mayor debilidad política de esta vía hacia la democracia vendría dada por su imposición externa y en este sentido acarrearía un problema de legimitidad mayor que el que tendría el escenario anterior. Sin embargo, sí se dispondría del poder suficiente para desmantelar las instituciones políticas y militares y otros rasgos del aparato autoritario del Estado. En este sentido, se cambiarían de un "plumazo" algunos de los obstáculos más importantes en un proceso de democratización. Pero veamos en detalle las características de este nuevo escenario:

1) El escenario del poder: Se formaría un régimen "títere" o "interino" que podría tener una duración indeterminada (Shain y Linz, 1995), impuesto por la administración norteamericana para posibilitar la transición democrática. El Partido Comunista cubano (PCC) y las FAR serían disueltos, clausurándose también la Asamblea Nacional Popular. Se produciría la detención y envío a Estados Unidos de los máximos dirigentes castristas y del propio Fidel Castro para su enjuciamiento. Se convocarían elecciones inmediatas sobre la base de alianzas políticas nuevas que dominarían los exiliados de Miami en conjunción con la oposición política interna, aunque ésta desempeñaría una posición subordinada frente a los primeros. En esta votación se prohibiría la participación del PCC, que terminaría siendo reconvertido en alguna opción pseudo-socialista para cooptar a parte de la élite de la antigua dirigencia castrista, y que otorgaría cierta credibilidad al nuevo régimen.

7. La Ley Helms-Burton contiene tres apartados, de los cuáles tres se dedican específicamente a la cuestión económica: I. Fortalecimiento de las sanciones económicas contra Cuba; II. Protección de los derechos de propiedad de los nacionales de Estados Unidos; III. Exclusión de ciertos extranjeros (negativa de visas para entrar a Estados Unidos a personas acusadas de "traficar" con propiedades reclamadas por norteamericanos). En su apdo. II. Ayuda a una Cuba libre e independiente, se reúnen las exigencias y requisitos que deben cumplirse para que el Presidente de los Estados Unidos determine que ya existe en Cuba un gobierno de transición. En mayo de 1998, los Estados Unidos y la Unión Europea decidieron cancelar los litigios en torno a las inversiones en Cuba producidos por la aplicación de esta Ley.

8. La oposición interna al régimen se ha ido conformando gradualmente durante los años ochenta, pero especialmente se ha organizado en la última década. La permanente represión por parte del Estado ha acentuado las divisiones y fragmentaciones de estos grupos que se han visto imposibilitados de actuar conjuntamente, salvo raras excepciones, como puede ser el Concilio Cubano, que surge en 1995 comprometiéndose con un proceso de cambio pacífico y respetuoso de la Constitución y las leyes o las organizaciones lideradas por la Iglesia católica cubana. 
2) La economía: Bajo la recomendación especial de Estados Unidos comenzarían las negociaciones para la reinserción de Cuba en los máximos organismos económicos internacionales (Fondo Monetario Internacional (FMI), Banco Mundial (BM), etc) y en los principales foros políticos latinoamericanos (la Organización de Estados Americanos, OEA) y mundiales (la Organización de Naciones Unidas, ONU). El Departamento de Estado norteamericano negociaría paralelamente con el régimen provisional cubano, no se esperaría al resultado electoral, un acuerdo para establecer lo más pronto posible un mecanismo que resuelva las reclamaciones por confiscación de bienes de los ciudadanos norteamericanos y cubanos tras la revolución de 1959. Así mismo, y en acuerdo con Estados Unidos, se trazaría un plan para ayudar a la reconstrucción de la economía cubana. Inmediatamente se iniciaría un tránsito de una economía socialista y planificada a una totalmente abierta a través de férreos planes de estabilización dictados por el FMI. Las consecuencias sociales de estas medidas sólo se tomarían en cuenta en un segundo plano, porque el primer objetivo trataría de restablecer el equilibrio macroeconómico y de ajustar el modelo cubano a uno de mercado? .

3) La ideología: El gobierno provisional encargado de la transición proscribiría todos los símbolos marxistaleninistas y castristas de los organismos públicos. Los medios de comunicación (radio, prensa, televisión) pasarían al control directo del gobierno de transición, bajo la tutela de Estados Unidos, hasta que se resolvieran las reclamaciones de los ciudadanos afectados por las expropiaciones de 1959. El mensaje fundamental dirigido a la sociedad civil por los medios sería que la libertad y la democracia han retornado definitivamente a la isla con el fin de la dictadura castrista.

4) Las relaciones internacionales: Se produciría el inmediato restablecimiento de las relaciones diplomáticas con Estados Undios, y con ello, el fin de la política norteamericana de ayuda al refugiado para contener la gran inmigración ilegal que estallaría después de la caída del régimen castrista. Aunque al principio pudiera producirse un cierto repudio hacia la intervención norteamericana en Cuba, por parte de México y otros países latinoamericanos, y especialmente por parte de la Unión Europea, rápidamente se producirá un fortalecimiento de la relaciones con la Unión Europea y otros países latinoamericanos, aunque es previsible que se generen graves tensiones por un cierto repudio hacia la intervención norteamericana en Cuba, por parte de México y otros países latinoamericanos, y especialmente por parte de la Unión Europea, rápidamente se producirá un fortalecimiento de la relaciones con la Unión Europea y otros países latinoamericanos, aunque es previsible que se generen graves tensiones al disponer la administración norteamericana la confiscación o congelamiento de los intereses económicos de las empresas europeas que invirtieron durante la época castrista. España sería una de las principales afectadas por esta medida, pero la reacción dependerá del tipo de gobierno que este país tenga en el momento de producirse las confiscaciones.
5) El papel de la sociedad civil: Es previsible un fraccionamiento en dos del comportamiento de la población. Una parte aceptaría las imposiciones norteamericanas, algunos con resignación, otros pensando en una inmediata mejora de su situación económica, pero un apreciable porcentaje, el más convencido de que la independencia de la isla estaría en peligro, pasaría a la clandestinidad iniciando una guerra civil contra el gobierno provisional y las fuerzas de intervención de Estados Unidos. Estos grupos alzados en armas estarían liderados por miembros de las disueltas FAR leales al régimen derrocado. Esta lucha adquiriría mayor popularidad al hacerse cada vez más evidente el deseo de Estados Unidos de "colonizar" la política y la economía cubana, volviendo a la fase política previa a 1959.

En suma, la improbabilidad de este escenario vendría dada por los riesgos y los costos que tendría que asumir el gobierno norteamericano tanto en el plano internacional como en el doméstico. Además, dado que uno de los rasgos más acentuados del régimen cubano es su ultranacionalismo y la irrebatible legitimidad de origen que tiene el castrismo desde 1959, no parece tarea fácil solventar a través de una intervención externa directa el tránsito hacia un proceso de democratización en Cuba.

\section{III}

Una tercera vía, a nuestro juicio poco probable, vendría dada por el inicio de un proceso de democratización en Cuba por decisión voluntaria del propio régimen castrista o post-castrista (la vía Gorbachov o como ha sido llamada por algunos autores cubanos, una perestroika tropical) ${ }^{10}$. Se trataría de una transformación dirigida desde dentro del régimen totalitario o autoritario en la que algunos de los grandes sustendadores del poder en el seno de la coalición autoritaria gobernante perciben que a consecuencia de las cambiantes condiciones del contexto internacional pero también nacional, sus intereses a largo plazo se persiguen mejor en un ámbito donde las instituciones autoritarias dan vía libre a las instituciones democráticas. Por supuesto, y como ya ha sido señalado (Stepan, 1986: 73) esta opción debe resolver importantes problemas que irán surgiendo en la medida en que se vaya produciendo una apertura política del régimen autoritario. Así, es probable que la gradual liberalización política conduzca a situaciones en las cuales sea más costoso tolerarlas y mediar entre los diferentes sectores que optar directamente por la pura y dura represión. Por otro lado, resulta también pre-

9. En mayo de este año, 1998, el ex-ministro socialista Carlos Solchaga sostuvo que los procesos de estabilización económica y de terapias de choque que serían necesarios para llevar a cabo estas transformaciones económicas no resultarían traumáticas porque la sociedad cubana ya había tocado fondo. Seminario "Cuba: escenarios económicos del postcastrismo" (24 de mayo de 1998), Instituto Universitario Ortega y Gasset.

10. Así la denomina José Bell Lara (1997:25), aunque en el contexto de su análisis la elección de esta vía hubiera significado el final de la Revolución: "En los hechos, el proceso de Rectificación inició una crítica práctica al modelo de socialismo real existente en Europa, desde la izquierda, desde la perspectiva de resolver los problemas del socialismo con métodos socialistas. Anoto de paso mi opinión personal que si la dirección cubana hubiera intentado una perestroika tropical entonces sí se hubiera cumplido la teoría del dominó y hoy no habría Revolución". 
visible que determinados sectores de la élite intenten construir reglas formales e informales que les garantizen sus intereses a pesar de que se produzca una transición democrática, esto puede conducir a la larga a una situación de democracia limitada. Por último, es probable que más que en ninguno de los escenarios previstos con anterioridad, el aparato de seguridad del Estado autoritario, fuerzas armadas, etc., intente preservar sus prerrogativas más allá del proceso de democratización.

Aún así, conviene analizar cuáles serían las distintas opciones para el caso cubano:

1) El escenario del poder: Se iniciaría un proceso de desacralización de la figura de Fidel Castro, una vez fallecido éste, junto con la inauguración de un período de autocrítica de la revolución cubana. Se daría así mismo un afianzamiento del nacionalismo anti-norteamericano para identificar al Partido Comunista como la única salida democrática posible para evitar el desastroso retorno al status quo previo a 1959. Las Fuerzas Armadas y la Asamblea Nacional serían reconvertidas en instancias políticas neutrales, al menos en el papel, para garantizar la credibilidad de la sociedad civil en el nuevo escenario político propuesto por los herederos de Castro. La Constitución cubana sería reformada para permitir el nuevo escenario político, pero se mantendrían principios sustantivos para los sectores de la élite política que controlarían el proceso de transición. Se abriría una ronda de negociación controlada por el régimen con algunas de las organizaciones de la oposición interna y externa, y se convocarían unas primeras elecciones pseudo-libres y pseudo-competitivas. La ventaja del régimen post-castrista es que podría salir fácilmente victorioso en un escenario constitutido por un débil e incipiente sistema multipartidista ${ }^{11}$. De este modo, el régimen postcastrista tendría grandes expectativas de conducir la transición democrática de acuerdo a sus objetivos si es que logran derrotar en las urnas a las fuerzas disidentes internas y a las opositoras del exilio cubano.

2) La economía: Se producirá una incorporación gradual a la economía de mercado con el patrocinio de la Unión Europea, Canadá, México y algunos países latinoamericanos. Cuba solicitará su ingreso en el FMI y Banco Mundial y la renegociación de su deuda externa. Se iniciarán asímismo negociaciones con la administración norteamericana sobre la base de no aceptar ninguna compensación o reparación económica para los exiliados. Se introducirá un programa de ajuste, con una liberalización financiera bastante rápida, pero el programa de privatizaciones se hará de un modo más ralentizado, tomándose en cuenta los costos sociales de estos procesos.

3) La ideología: persistencia de la doctrina nacionalista basada en el aliento de la figura de Martí, desplazamiento vertiginoso de los idearios de la doctrina marxistaleninista e inicio de un proceso de crítica al personalismo de Fidel Castro.

4) Las relaciones internacionales: Se producirá un ablandamiento del embargo norteamericano, aunque el restablecimiento de las relaciones con Estados Unidos se mantiene en suspenso mientras se realizan las nego- ciaciones encaminadas a resolver el contencioso sobre las confiscaciones económicas a los exiliados. Las relaciones con la Unión Europea se fortalecen, mientras se diseñan estrategias legales para proteger la inversión privada y pública, realizada ésta última durante el régimen castrista en los noventa.

5) El papel de la sociedad civil: Esta actuaría fragmentada en este escenario de apertura política, ya que los más desencantados con el régimen expresarían públicamente sus discrepancias alineándose con los grupos políticos constituídos por los disidentes, entre tanto que otro porcentaje de la población más temeroso del futuro incierto continuaría apoyando al Partido Comunista Cubano. Algunos grupos radicalizados podrían pasar a la clandestinidad para forzar desde la lucha armada (ahí sí cabría algún llamamiento a favor de una intervención extranjera) la caída definitiva del régimen post-castrista.

Este tercer escenario tendría como hemos señalado severos condicionantes tanto en el orden interno como en el externo, y llevaría a un fraccionamiento importante tanto de los sectores de apoyo al nuevo régimen post-castrista como entre los sectores de oposición. En este contexto, de división entre continuistas y oposición, podría ser factible una revigorización del papel desempeñado por las FAR y en este sentido, un retroceso del proceso de transición, o un condicionamiento total y absoluto de éste.

\section{IV}

Hemos dejado en último lugar, un escenario que consideramos más que probable y que sólo será posible si se constata que las reformas hacia el mercado implantadas a comienzos de los años noventa han llevado a un cambio del sistema económico en Cuba sin afectar al régimen político (Mesa-Lago, 1997). Cuba "se abrirá al mundo" ofreciendo la apertura económica a cambio de la salvaguardia de las conquistas sociales logradas por el régimen castrista. Esto implicaría a la vez la preservación política de los líderes post-castristas en el control del aparato estatal, continuándose con el ensayo de la democracia socialista inaugurada por Fidel Castro (la vía Deng Xiaoping). Necesariamente ocurriría una vez que Fidel Castro, por muerte o por retiro voluntario, desapareciera del poder. El nuevo liderazgo de la Cuba post-castrista iniciaría una ronda de conversaciones con la administración norteamericana para intentar descongelar las relaciones diplomáticas a cambio de un proceso acelerado de apertura económica hacia el exterior.

1) El escenario de poder: la nueva dirección post-castrista ofrece la “destotalización"(H. Arendt) del Estado a cambio del apoyo externo para aliviar su crónica crisis económica. En este contexto, es previsible el crecimiento de la influencia política de las Fuerzas Armadas sobre los órga-

11. Como se ha señalado con acierto los partidos políticos en el exilio -el Demócrata Cristiano, la Coordinadora Socialdemócrata y la Unión Liberal- han debido concentrarse en responder a las demandas políticas de la emigración. La capacidad de la disidencia interna para organizarse en partidos políticos ha sido nula debido a la represión del régimen cubano (Rojas, 1997). 
nos directivos del Partido Comunista. A diferencia de nuestro primer escenario, en el que el cambio al autoritarismo es un objetivo no deseado, en éste se consolida voluntariamente desde la esfera del poder un régimen autoritario como el mal menor para la salvación del sistema de poder post-castrista. Se profundiza el modelo castrista de democracia socialista practicado ya en el decenio del noventa (elecciones periódicas controladas por el PCC para renovar la Asamblea Nacional Popular y los gobiernos locales).

2) La economía: Es el sector donde principalmente van a concentrarse todas las innovaciones del régimen postcastrista. En principio, y dado que los nuevos sustentadores del poder persiguen dotarse de una nueva legitimidad de arranque, se aplicaría un programa económico heterodoxo (de corte populista) para aliviar la crisis de la economía doméstica, pudiendo significar ello el fin de los planes quinquenales y de la economía planificada socialista. Se estudian los programas de ajuste económico de los organismos internacionales (en especial del Banco Mundial) para encaminarse a una de economía de shock liberal en caso de fracasar el populismo económico. Quizás sea en este punto, donde la aplicación de un modelo económico similar al chino parece más difícil. Así, se han señalado que a pesar de las similitudes las diferencias entre ambos casos son enormes (Fogel, 1997) ${ }^{12}$.

3) La ideología: Se producirá un reforzamiento de la doctrina nacionalista sobre la base de la difusión y preservación de los idearios de Martí y Castro. Se mantendrá el culto a la personalidad de Fidel Castro como el padre de la Nueva Cuba. Pero disminuye en cambio dentro de este ideario la "demonización” de Estados Unidos con el fin de posibilitar una más que probable reanudación de las relaciones diplomáticas, y sobre todo, económicas.

4) Las relaciones internacionales: En esta coyuntura, tanto la Unión Europea, como Canadá y México, principales inversores extranjeros hasta el momento en la economía cubana, desempeñarán un papel fundamental. El embargo norteamericano se suavizará pero no va a desaparecer mientras el gobierno de Cuba no dé señales de una apertura política que complete y complemente las reformas económicas. De este modo, se producirá el inicio de una ronda de negociaciones entre emisarios cubanos y norteamericanos sobre la base de que Cuba exige el apoyo de Estados Unidos para su reinserción en los organismos internacionales y el acceso al crédito internacional, mientras éste último pide que el régimen post-castrista reconozca las reclamaciones económicas de los exiliados y de los ciudadanos norteamericanos.

5) El papel de la sociedad civil: Crecen los movimientos disidentes anti-castristas dentro de la isla que en la clandestinidad se preparan para formar alianzas que cuentan con el apoyo de la Iglesia Católica. Es probable el aumento de las huelgas en contra de los ajustes económicos como manifestación más clara de la pérdida del control del Estado sobre el comportamiento de la población. Se producirá un recrudecimiento de la emigración clandestina hacia Estados Unidos entre la población más desesperada o afectada por los ajustes económicos.

Este último escenario plantea en sí mismo múltiples preguntas, difíciles de contestar en la coyuntura actual. Si bien es evidente que ha sido posible hasta el momento en China, no resultaría tan factible en un país como Cuba, mucho más próximo geopolíticamente hablando a Estados Unidos y de una importancia económica muchísimo más reducida que el anterior; por otro lado, tampoco podemos contestar fiablemente a la pregunta de si sería viable una especie de "perestroika" económica hacia afuera sin una "glasnot" en el frente interno. Todo ello nos hace pensar que aunque es posible que para las élites internas sea una opción deseable, existen serias dificultades para que pueda iniciarse en Cuba.

\section{CONCLUSIONES}

En las páginas anteriores hemos intentando esbozar cuáles podrían ser a nuestro juicio los posibles escenarios de una transición política en Cuba, algunos más probables o verosímiles que otros, pero todos ellos responden en alguna medida a los intereses de determinados sectores dentro y fuera del régimen castrista. En ninguno de los casos anteriores, hemos otorgado un papel totalmente autónomo a la oposición política, dado que en principio éste no sería un escenario previsible en un futuro cercano, sino más bien sería una posible consecuencia de la evolución de un régimen autoritario. Nos gustaría aclarar asî mismo que en ningún caso consideramos al régimen de Castro como un sistema monolítico, sino que responde más bien al juego de distintos actores institucionales, políticos, sociales y económicos, y que este juego ha sufrido considerables cambios desde el triunfo de la revolución en 1959 hasta la actualidad, muy especialmente debemos tener en cuenta los acaecidos durante la década de los años noventa porque ellos van a condicionar el desarrollo futuro de estos escenarios. En este sentido, no cabe considerar al castrismo como un ejemplo típico de caudillismo tradicional o de dictadura personalista, sino más bien como un régimen autoritario con un fuerte componente nacionalista y carismático. Por otro lado, la velocidad, secuencia y graduación de los cambios no va a ser la misma en todos los ámbitos que hemos definido (el escenario de poder, la economía, la ideología, las relaciones internacionales y la sociedad civil)

12. China, pero también Vietnam, hicieron una salida temprana hacia un cambio fuerte y arriesgado, y empezaron la reforma en el campo, con una descolectivización de la agricultura que provocó una fuerte subida de la producción alimentaria y de las cosechas para la exportación. En Cuba, el camino fue el contrario, y sólo en septiembre de 1995 se crearon los mercados agropecuarios. China y Vietnam permitieron que la inversión desde afuera, mucho mayor en ambos casos, se produjera en indus trias manufactureras con una amplia mano de obra, lo que posibilitaba, a través de los salarios, difundir riqueza en el conjunto de la población. En Cuba, por su parte, las inversiones se han producido hasta el momento en sectores como el turismo, que no utilizan mucha mano de obra. Así, el crecimiento de los ingresos lo aprovecha principalmente el Estado y sólo llega a la sociedad de una manera indirecta. Por último, ambos países, China y Vietnam realizaron una apertura fulminante al mercado financiero y regularizaron desde un primer momento sus relaciones con los organismos de crédito internacional. Como vemos, éste no ha sido el caso cubano. 
y ello puede provocar que las imágenes de los distintos escenarios queden inconclusas, y que en su lugar, algunas de las características que hemos considerado queden en meros perfiles o proyecciones sin llegar a cuajar definitivamente. Por otro lado, en la peculiar evolución o transformación que se está produciendo en Cuba, una buena parte de las estructuras políticas, sociales y económicas se han mostrado especialmente resistentes a los nuevos embates del Estado y de la sociedad, y es probable que no terminen de desaparecer del todo hasta que no se haya producido un reemplazo total del régimen político por otro tipo totalmente nuevo. Pero en todo caso hemos intentado ofrecer una imagen de la interrelación de los distintos actores en un hipotético tránsito hacia la democratización en Cuba y hemos cuestionado la validez y limitaciones de los modelos de transición que se han producido con anterioridad en otros contextos como el del Sur de Europa, América Latina y Europa del Este.

\section{REFERENCIAS BIBLIOGRÁFICAS}

ARENDT, H. (1980), El totalitarismo, Madrid: Alianza Ed. Bell LaRA, José (1997) (con C. Pulido Escandell), Visión desde Cuba, Gijón: Sodepaz-Asturias.

DOMÍNGUEZ, JORGE I. (1997), “¿Comienza una transición hacia el autoritarismo en Cuba?", en Encuentro de la Cultura Cubana, nos. 6/7, otoño/invierno, pp. 7-23.

FOGEL, JEAN-FrANÇOIS (1997), "La transición económica en Cuba: eludiendo los caminos europeos y asiáticos", en Encuentro de la Cultura Cubana, nos. 6/7, otoño/invierno, pp. 142-155.
LiNZ, J. J. (1964), "An Authoritarian Regime: The Case of Spain”, en Erik Allardt \& Yrjö Littunen (Eds.), Cleavages, Ideologies and Party Systems, Helsinki: Transactions of the Westermarck Society, pp. 291-342.

- (1970): "From Falange to Movimiento-Organización: The Spanish Single Party and the Franco Regime, 1936-1968”, en Samuel P. Huntington \& Clement H. Moore (Eds.), Authoritarian Politics in Modern Society: The Dynamics of Established One-Party Systems, New York: Basic Books, pp. 128-203.

- (1975), "Totalitarian and Authoritarian Regimes", en Fred I. Greenstein \& Nelson W. Polsby (Eds.), Handbook of Political Science, Reading, Mass.: Addison-Wesley Publishing Co., 3:175-411.

Linz, J. J. \& Stepan, A. (1997), Problems of Democratic Transition and Consolidation, Baltimore \& London: The John Hopkins University Press.

Mesa-Lago, Carmelo (1997), “¿Cambio de régimen o cambios en el régimen? Aspectos políticos y económicos", en Encuentro de la Cultura Cubana, nos. 6/7, otoño/invierno, pp. 36-43.

Rojas, Rafael (1997), "Políticas invisibles", en Encuentro de la Cultura Cubana, nos. 6/7, otoño/invierno, pp. 24-35.

Shain, Yossi \& LinZ, J. J. (1995), Between States: Interim Governments and Democratic Transitions, New York: Cambridge University Press.

STEPAN, A. (1986): "Paths toward Redemocratization: Theoretical and Comparative Considerations", en Guillermo O’Donnell, P. C. Schmitter \& L. Whitehead (Eds.), Transitions from Authoritarian Rule. Comparative Perspectives, Baltimore \& London: The John Hopkins University Press, pp. 64-84.

\section{RESUMEN}

Este artículo trata de mostrar las cuatro diferentes coyunturas en términos de oportunidades políticas, sociales, ideológicas y económicas para la transición política en Cuba. Así, proponemos que las posibilidades de cada uno de estos escenarios dependerán de la estrategia de poder, las opciones económicas, los cambios ideológicos, las relaciones internacionales y el comportamiento de la sociedad civil.

Palabras claves: transición política, totalitarismo, autoritarismo, postotalitarismo, nacionalismo carismático, dictadura, intervención norteamericana, apertura política, apertura económica.

\section{ABSTRACT}

This article tries to offer four different conjunctures in terms of political, social, ideological and economical choices for the political transition in Cuba. Therefore, we propose that the possibilities of each other of these ones will depend from the power-holders, the economical choices, the ideological changes, the international relations and the civil society behaviour.

Key words: political transition, totalitarianism, autoritarianism, postotalitarianism, charismatic nationalism, 